klagten gewettet wird. Allein dieses Urtheil wird auf Verlangen der Klägerin als ein falsum iudicium aufgehoben (cf. Glanvilla 14, 1, $§$; 14, 6, Bracton f. 142b). Durch Wahrspruch einer Jury wird nun das originäre Eigenthum der Klägerin an den drei Schweinen festgestellt und sodamn der Beklagte gehangen. Die Jury wurde nicht über die Schuldfrage, sondern nur äber die Eigenthumsfrage vernommen. Eine Ueberführung des Beklagten war nicht mehr nöthig. Denn wenn das originäre Eigenthum der Klägerin feststand (die Schweine waren von ihrer Zucht), konnte der Beklagte sich von dem Vorwurf des Diebstahls nur durch den Zug auf einen Gewährsmann befreien. Er hatte es aber unterlassen, sich gegen die Klägerin auf einen Gewährsmann zu berufen, vielmehr bestritten, dass die Schweine jemals ihr Eigenthum gewesen seien und sie dadurch genöthigt, die Diebstahlsklage zu erheben, gegen die er gleichfalls keinen Auctor ins Treffen führte.

Die angeführten Beispiele dürften genügen, um darzuthun, dass das Note Book eine englische Rechtsquelle ersten Ranges ist. Möge der Wunsch des Herausgebers nach einer wahrhaft kritischen Ausgabe Bractons bald in Erfüllung gehen. Er hat ihr durch das Note Book und durch seine Einleitung zu demselben tüchtig vorgearbeitet und sich als einen scharfsinnigen Kenner des anglonormannischen Rechts von seltener Gründlichkeit legitimirt.

Heinrich Brunner.

\title{
Verzeichniss \\ der von 1887 bis 1888 erschienenen Litteratur der älteren skandinavischen Rechtsgeschichte.
}

\section{Quellen.}

A. Unmittelbare Rechtsquellen.

Dänemark: Secher, V. A., Corpus constitutionum Daniae. Forordninger, Recesser og andre Kongelige Breve, Danmarks Lovgivning vedkommende 1558-1660. Bd. I, 1-3. Kopenhagen 1887, 1888.

Norwegen: Pappenheim, M., Ein altnorwegisches Schutzgildestatut S. $145-167$ (s. u. IV).

B. Mittelbare Rechtsquellen.

Dänemark: Schäfer, D., Das Buch des Lübeckischen Vogles auf Schonen. Halle 1887.

Schıeden: Svenska riksarchivets pappershandlingar 1351-1400, förtecknade med angifvande af innehållet. Stockholm 1887.

Norwegen: Diplomatarium Norvegicum XII, 2. 1888.

Huitfeldt-Kaas, H. J., Norske Regnskaber og Jordebøger fra det 16 de Aarhundrede I. Christiania 1885-1887.

Island: Storm, G., Islandske Annaler indtil 1578. Christiania 1888. 
Britische Inseln: Vigfusson, G., Icelandic Sagas and other historical documents relating to the settlements and descents of the Northmenn on the British isles. 2 vol. London 1887.

\section{Quellengesehichte.}

Wimmer, L. F. A., Die Runenschrift, 2. Aufl., übersetzt von F. Holtbausen. Berlin 1887.

\section{Allgemeine Rechtsgeschichte.}

Ficker, J., Ueber nähere Verwandtschaft zwischen gothisch-spanischem und norwegisch-isländischem Recht. Innsbruck 1887 (Mittheilungen des Instituts für österreichische Geschichtsforschunğ, II Ergänzgsbd. 455-542, auch als Separatabdr.).

\section{Verfassungsgeschichte.}

Lehmann, K., Die Gastung der germanischen Könige (in Abhandlungen zur germanischen, insbesondere nordischen Rechtsgeschichte. Berlin 1888).

Dänemark: Maurer, K., Das angebliche Vorkommen des Gesetzsprecheramtes in Dänemark (Sitzungsber. der Kgl. bayer. Acad. der Wiss. Philos.-philol. Gl., 1887, II, 3, S. 363-399).

Norwegen: Lehmann, $\mathbf{K}$., Der Ursprung des altnorwegischen Sysselamtes (in Abhandlungen etc.).

Pappenheim, M., Ein altnorwegisches Schutzgildestatut, nach seiner Bedeutung für die Geschichte des nordgermanischen Gildewesens erläutert. Breslau 1888.

Taranger, A., Om Betydningen af Herad og Herads - Kirkja i de ældre Kristenretter (Norsk historisk Tidsskr. VI, $337 \mathrm{ff}$,, auch als Separatabdr. Christiania 1887) ${ }^{\mathbf{1}}$ ).

Island: Maurer, K., Die Rechtsrichtung des älteren isländischen Rechts (Festgaben der Münchener juristischen Facultät für J. W. Planck, 1887, S. 119 ff.).

Finsen, V., Om den oprindelige Ordning af nogle af den islandske Fristats Institutioner. Kopenhagen 1888 (Vidensk. Selsk. Skıifter 6 Række, histor. og philosophisk Afd. II, 1).

\section{Geschichte des Strafrechts.}

Island: Maurer, K., Vigslóđi (Arkiv för Nordisk filol. N. F. I, 98 ff.).

\section{Geschichte des Privatrechts.}

Schweden: Lehmann, K., Die altschwedischen Festiger (in Abhandlungen etc.).

Norwegen: Maurer, K., Bidrag til Læren om Tak (Tidsskr. for Retsvidensk. I, S. 308 ff.).

Hingewiesen sei zum Schluss auf die von Professor Fr. Hagerup in Christiania in Gemeinschaft mit Afzelius, Bergh, Goos, Lassen und

1) Bemerkt sei an dieser Stelle zugleich. dass von E. Sars, Udsigt over den norske Historie 1887 der dritte Band erschienen ist. 
Trygger seit 1888 herausgegebene Zeitschrift für Rechtswissenschaft (Tidsskrift for Retsvidenskab), von der die drei ersten Hefte des ersten Jahrgangs vorliegen. Die Zeitschrift bezweckt, Abhandlungen aus allen Gebieten des Rechts, also auch der Rechtsgeschichte, zu bringen. Die vorliegenden Hefte enthalten u. a. von E. Hertzberg ausführliche Besprechungen rechtshistorischer Arbeiten Deutscher über norwegische Rechtsgeschichte aus den Jahren 1886, 1887 und von Maurer die oben unter VI genannle Arbeit.

Rostock, im September 1888. Karl Lehmann.

Monumenta Germaniae Historica. Legum Sectio I. Legum Nationum Germanicarum Tomi V. Pars I. Leges Alamannorum edidit Karolus Lehmann. Hannover, Hahn. 1888. 176 SS. $4^{0}$.

Die Neuausgabe der Leges Alamannorum eröffnet den Rejgen der in Quarlausgaben von der Monumentendirection geplanten Editionen von Volksrechten. Von den fünf Bänden solcher Quartausgaben, in denen die sämmtlichen Volksrechte, sei es in erster, sei es in neuer Edition, untergebracht werden sollen, sind die vier ersten Bände für die Volksrechte der Gothen, Burgunder, Langobarden und Franken bestimmt. Die Leges Alamannorum dagegen sollen mit den sonstigen rechtsrheinischen Volksrechten den fünften Band füllen.

Dem Herausgeber wurde die Neuausgabe der Leges Alamannorum im Jahre 1884 anvertraut auf Grund einer im Neuen Archiv Bd. X veröffentlichten Abhandlung, welche dessen Grundanschauungen über die Textgestaltung des alamannischen Volksrechtes wiedergab. Er begann seine Arbeit im Laufe des Sommers 1884 und führte sie zum Ende im Frühjahr 1887. Die Drucklegung nahm den Zeitraum vom Frühjahr 1887 bis zum Frühjahr 1888 in Anspruch.

Feste Vorschriften waren dem Herausgeber hinsichtlich der Vorbereitung des Werkes nur insofern ertheilt, als sich die äussere Ausstattung der Ausgabe, insbesondere der Apparat an sachlichen Noten innerhalb der für die Quartausgaben gesteckten Grenzen halten und als eine nochmalige Collation nicht sãmmtlicher von Merkel bereits benutzter, sondern nur der wichtigeren Handschriften stattfinden sollte.

Nachdem der Herausgeber die Arbeit zum Drucke fertig gestellt hatte, trat sie statutengemäss unter die Controle des ständigen Leiters der Abtheilung „Leges“, als welcher Herr Professor Brunner, und eines ad hoc beigeordneten Mitarbeiters, als welcher Herr Dr. Zeumer fungirte. Die Geschäftsvertheilung war in der Art geordnet, dass Herr Dr. Zeumer bei jedem Druckbogen Text und Noten zunächst vom Standpunkte der äusserlichen, dann aber auch ohne Verlassen der einmal acceptirten Grundlage vom Standpunkte der höheren Kritik revidirte und gegebenen Falls nothwendig erscheinende Aenderungen vorschlug, 